\title{
Inoculum and Infection Dynamics of Polystigma amygdalinum in Almond Orchards in Spain
}

\author{
Erick Zúñiga, ${ }^{1,2}$ Joaquín Romero, ${ }^{3}$ Andrés Ollero-Lara, ${ }^{3}$ María Lovera, ${ }^{4}$ Octavio Arquero, ${ }^{4}$ Xavier Miarnau, ${ }^{5}$ Laura Torguet, ${ }^{5}$ \\ Antonio Trapero, ${ }^{3}$ and Jordi Luque ${ }^{1, \dagger}$ \\ ${ }^{1}$ Plant Pathology, IRTA Cabrils, 08348 Cabrils, Spain \\ 2 Plant Physiology Laboratory, Universitat Autònoma de Barcelona, 08193 Bellaterra, Spain \\ ${ }^{3}$ Departamento de Agronomía, ETSIAM, Universidad de Córdoba, 14071 Córdoba, Spain \\ ${ }^{4}$ Departamento de Fruticultura Mediterránea, IFAPA, 14004 Córdoba, Spain \\ ${ }^{5}$ Fruit Production Program, IRTA Fruitcentre, PCiTAL, 25003 Lleida, Spain
}

\begin{abstract}
Red leaf blotch (RLB) disease of almond, caused by Polystigma amygdalinum, is an important foliar disease in most production regions of the Mediterranean basin and the Middle East because severe infections may cause a premature defoliation of the tree. Some key aspects on the epidemiology of $P$. amygdalinum were studied in multiyear trials in two almond-growing regions in Spain, which included the seasonal development of perithecia and production and germination of ascospores along with the disease incubation and plant infectivity periods. Our results showed that primary inoculum was available in extended periods (January to August). Significant differences in ascospore amounts among

the development of $P$. amygdalinum perithecia. Variable ascospore germination rates were observed from April to July: $>15 \%$ but rarely exceeding 30\%. The RLB infectivity period in Catalonia extended from March to mid-June, whereas in Andalusia it was from March to May. The incubation period was mainly in a range of 5 to 10 weeks in Catalonia. The environmental conditions of October to January influence the available ascospore amounts in the next season. RLB infection occurs in spring to summer when mean temperatures are in the range 10 to $20^{\circ} \mathrm{C}$. These results represent the first step in developing a prediction model of the disease that might serve as a tool for the control of RLB.
\end{abstract} regions, higher in the southern Andalusia and lower in the northern Catalonia, and years of study were detected. The factors geographical location, sampling period, and evaluation year were found significant on
Keywords: epidemiology, Polystigma amygdalinum, primary inoculum, Prunus dulcis, red leaf blotch, tree nuts
Almond (Prunus dulcis [Mill.] D.A. Webb) is a traditional and widespread crop in the Mediterranean basin and the Middle East. It is generally considered a marginal crop in this area; it is currently grown in dry land under limiting soil and climate conditions, which leads to low yields. Spain leads the world in area under almond cultivation, with $>630,000$ ha of almonds grown in 2017 (FAOSTAT 2019; MAPA 2019). However, the Spanish annual yield of almonds with shell is slightly $>400 \mathrm{~kg} \mathrm{ha}^{-1}$, much lower than that obtained in the United States, the leading producer country in the world with an average production $>2,500 \mathrm{~kg} \mathrm{ha}^{-1}$ (FAOSTAT 2019). Intensive almond cropping in Spain has been driven by a general increase in world nut consumption (Miarnau et al. 2010, 2018). This intensive cropping is characterized by the use of new almond cultivars planted in higher tree density, and it is supported with proper irrigation, fertilization, and pesticide programs to reach higher yields (Miarnau et al. 2018; Vargas et al. 2010), comparable with that obtained in the United States (MAPA 2019). However, there is a great concern about an eventual increase in the incidence of almond diseases, which have become

${ }^{\dagger}$ Corresponding author: J. Luque; jordi.luque@irta.cat

Funding: Research was funded by Instituto Nacional de Investigación y Tecnología Agraria y Alimentaria (INIA), Spain grants RTA2013-00004C03-01 and RTA2017-00009-C04-01 with matching funds from the European Regional Development Fund. E. Zúñiga was supported by Consejo Nacional de Ciencia y Tecnología with a predoctoral grant. X. Miarnau, L. Torguet, and J. Luque, were partially supported by Agència de Gestió d'Ajuts Universitaris i de Recerca CERCA Programme, Generalitat de Catalunya (Spain).

The author(s) declare no conflict of interest.

Accepted for publication 18 November 2019.

(C) 2020 The American Phytopathological Society the main limiting factor of these new plantations (Ollero-Lara et al. 2016a, 2019; Torguet et al. 2016).

Red leaf blotch (RLB) of almond, caused by the ascomycete Polystigma amygdalinum P.F. Cannon, is a foliar disease that is widely extended among most almond production regions of Europe and Asia (Cannon 1996; Farr and Rossman 2019), where it is considered of high economic relevance in several countries (Cannon 1996; Saad and Masannat 1997). The disease is endemic in these regions, and it is not yet known in other almond-growing areas in the world, such as the United States or Australia (Farr and Rossman 2019). Although RLB has been well known in Spain since 1927 (González-Fragoso 1927), its incidence has increased worryingly during the last years and is currently considered a reemerging disease in the new intensive almond plantations (Almacellas 2014; Ollero-Lara et al. 2016a; Torguet et al. 2016). It has been hypothesized that increased incidence of RLB could be related to the better growing conditions for almond cropping in the new intensive plantations as well as the use of new late-flowering cultivars (especially cultivar Guara in Spain), which are more susceptible to RLB than traditional ones (Ollero-Lara et al. 2016b, 2019). First RLB symptoms appear as pale green to yellowish spots on both leaf sides in spring, turning into yellowish orange and later, dark brown spots with age. Size of leaf spots increases through the spring and summer seasons, and they cover almost the whole leaf surface in late summer under favorable weather conditions. These spots are commonly associated with hypertrophy and deformation of leaves caused by the development of the fungal stroma on leaves. Occasionally, severe infections under hot and dry conditions can induce an early leaf fall in summer, thus reducing the photosynthetic activity of trees.

$P$. amygdalinum is a biotrophic ascomycete specific to almond, which was first described in 1845 in Italy as Septoria rubra var. amygdalina; it was later reclassified within the genus Polystigma as Polystigma ochraceum or Polystigma rubrum, mainly because of the color of the fungal stroma in the leaves (Cannon 1996). The species $P$. amygdalinum differs from other Polystigma species, 
which affect numerous species of the Prunus genus owing to its host specificity, stromal coloration, and the morphology of fruiting bodies and spores (Cannon 1996). Because of its host specificity, the limited geographical distribution, and the inability to grow in artificial media, research on P. amygdalinum is scarce (Cannon 1996). A phylogenetic study in 2015 indicated that $P$. amygdalinum might not belong to the Phyllachorales, which it had been considered to date, and should be better accommodated in the Xylariomycetidae subclass of Sordariomycetes, close to Xylariales and Trichosphaeriales (Habibi et al. 2015).

The RLB disease is monocyclic, and the only inoculum sources are the stromata of affected leaves that fall to the ground in autumn (Banihashemi 1990; Ollero-Lara et al. 2016b; Saad and Masannat 1997). The sexual stage is developed in winter on the leaf stromata, and later in spring, ascospores are air spread and can infect new almond leaves (Banihashemi 1990). In Iran, Ghazanfari and Banihashemi (1976) reported on the influence of autumn and winter weather conditions in perithecia development. Based on these authors, the start of perithecia maturation occurs at $<10^{\circ} \mathrm{C}$. Banihashemi (1990) showed that ascospore release in Iran is related with rain periods beginning at flowering and reaching the maximum at petal fall (late April to early May). In Lebanon, ascospore release can occur between February and mid-May (Saad and Masannat 1997). However, the effect of weather conditions on the infection process is deeply unknown. After infection, leaf spots appear after an incubation period of 30 to 35 days (Banihashemi 1990; Cannon 1996; Suzuki et al. 2008). The occurrence of secondary cycles has not been confirmed (Ollero-Lara et al. 2016b; Saad and Masannat 1997; Shabi 1997) because conidia do not have infective ability, and their only function seems to be to act as spermatia in the sexual reproduction of the pathogen (Cannon 1996; Habibi and Banihashemi 2016).

As a monocyclic disease, control management of RLB should be aimed at (i) reducing primary inoculum potential (i.e., ascospores produced in the affected leaves fallen in previous autumn), and (ii) protecting new almond leaves growing in the season. Based on several authors (Almacellas 2014; Arquero 2013; Lin and Szteinberg 1992), the control measures to achieve the first objective include (i) to remove or bury the leaves, (ii) to favor their decomposition through urea applications, and (iii) to treat fallen leaves with fungicides. However, none of these measures have been evaluated for almond crop in Spain (Ollero-Lara et al. 2016b). Regarding the second objective, application of fungicides seems to be the most effective measure to protect the new leaves from RLB infections (Almacellas and Marín 2011; Arquero 2013; Bayt-Tork et al. 2014). For all of the above control measures to be effective, it is necessary to know the dynamics of the inoculum potential in fallen leaves and the conditions influencing ascospore production, dispersal, and infection. A decision support system considering the monocyclic pattern of the RLB epidemics might be a helpful tool to optimize fungicide applications.

The objective of this study was to characterize the dynamics of the production, maturation, and potential dispersion of $P$. amygdalinum ascospores and correlate the key aspects of the disease with the environmental conditions in two Spanish almond-growing regions, namely Andalusia and Catalonia. These two areas are highly representative of the main almond-growing areas in Spain (South and Ebro Valley, respectively).

\section{Materials and Methods}

Geographical locations. Three experimental sites were located as follows: one location in Córdoba, Andalusia (southern Spain; World Geodetic System coordinates: Universal Transverse Mercator (UTM) 30S $X=341,069, Y=4,190,753$ ) and two locations in Catalonia (northeastern Spain), namely Gandesa (UTM $31 \mathrm{~T} X=284,000$, $Y=4,549,200$ ) and Les Borges Blanques (Borges hereafter; UTM $31 \mathrm{~T} X=320,870, Y=4,597,530)$. These sites corresponded to experimental almond orchards located at facilities of Instituto de Investigación y Formación Agraria y Pesquera de Andalucía (IFAPA) (Andalusia) and Institut de Recerca i Tecnologia Agroalimentàries (Catalonia). Orchards consisted of trees of different national and foreign cultivars variously arranged and managed under local usual practices. Trees in the orchards were not treated with any chemical product to allow natural infection of leaves by $P$. amygdalinum.

Plant material. For the experiments on primary inoculum monitoring, development of fruiting bodies, and germination of ascospores, fallen leaves of various almond cultivars with distinct RLB symptoms were collected during early autumn (September) in Andalusia and autumn/winter (December to January) in Catalonia before each specific experiment. Because the experimental orchards consisted of different almond cultivars, collected fallen leaves from the ground could not be classified according to their cultivar origin. In each season, an additional bulk sample of leaves collected in Gandesa was taken to Borges to study the eventual environmental influence in samples from different geographical origins. This sample (hereafter as Borges/ Gandesa) was considered as a third location within the Catalonian sites. In all experimental sites, leaves were placed into nylon mesh bags with 90 to 200 leaves per bag. The bags with fewer leaf numbers were processed earlier in the season, whereas the bags with higher amounts of leaves were processed later in the season because natural decomposition of leaves along the time would have left a low sample amount at later stages. The bags were left outdoors in the orchard by nailing them on the ground. Various numbers of bags $(n>13)$ were prepared for each experimental site and year.

For the monitoring of natural infections and the estimation of the disease incubation period, 1-year-old plants of the susceptible cultivar Tarraco grafted onto cultivar GF-677 rootstock were used. Trap plants were kept in greenhouses while not being exposed to natural RLB infections in the experimental sites, whereas another group of plants (control plants) was never moved out of the greenhouse. Regardless their geographical location, plants kept in the greenhouses were maintained in 3-liter pots with a peat:perlite mixture of 3:1 (vol/vol; peat: Floratorf TKS1, Floragard; perlite: Europerl). The substrate was amended with Osmocote Pro 3-4M granular fertilizer (Everris) at $2.5 \mathrm{~g} \mathrm{liter}^{-1}$. Plants were irrigated as needed to avoid water stress, and they were never treated with fungicides both in the greenhouse and in the experimental sites.

Monitoring of primary inoculum. The study of primary inoculum was conducted for three seasons in Andalusia (2014 to 2016) and Catalonia (2015 to 2017). Starting from winter in each year at the stage of dormant trees, the bags of leaf samples were taken fortnightly to the laboratory until the end of the trial. The sample was oven dried for $24 \mathrm{~h}$ at $35^{\circ} \mathrm{C}$. Each sample was weighed (dry weight) and later subdivided into eight equally weighted subsamples. In Andalusia, all eight subsamples were treated separately for ascospore extraction in distilled water by crushing leaves in a mortar until getting a homogeneous suspension (about a 10-min operation). In Catalonia, an additional ascospore extraction method was tested by continuous stirring ( $18 \mathrm{~h}$, room temperature) of a suspension of leaf fragments in water. Thus, in Catalonia, four subsamples were extracted by crushing, and the remaining four were extracted by stirring. In all cases, various amounts of distilled water were used according to the sample weight (about $40 \mathrm{ml} / \mathrm{g}$ of sample). For both extraction methods, final ascospore suspensions were filtered through a two-folded 60- $\mu \mathrm{m}$ Nylon mesh, and subsamples of ascospore suspensions were examined under a microscope $(\times 250)$ using a hemocytometer (Neubauer chamber). Ascospores of $P$. amygdalinum were unambiguously identified through their morphology features and counted. Each subsample was measured four times, and eight replicated measurements were done per subsample measurement. Results were expressed as numbers of ascospores per gram (dry weight) of leaves after proper calculations. The experimental period covered from January to August for all combinations of year and location.

Development of fruiting bodies. This study was conducted with the leaf samples collected in Catalonia in 2016 and 2017. Prior to the oven drying of leaf samples, four leaves with well-developed fungal stromata were taken from each sample bag. The outer part of the fungal stroma was cut off with a sterile scalpel, and five randomly chosen fruiting bodies from each leaf were individually excised with a hypodermic needle. The fruiting bodies were placed in a water droplet on a microscope slide and bisected to unveil their content; then, 
they were covered with a coverslip and examined under a light microscope $(\times 250)$. The fruiting bodies ( 20 per each location and sampling period) were classified into six different developmental stages by using the modified categories described by Toscano-Underwood et al. (2003) as follows: class P (pycnidia, either with conidia or not); class A (perithecium differentiated, asci undifferentiated or beginning differentiation, ascospores undifferentiated); class B (perithecium differentiated, asci differentiated, ascospores undifferentiated); class $\mathrm{C}$ (perithecium differentiated, most asci differentiated, some ascospores [fewer than eight] differentiated); class D (fully matured perithecium, asci differentiated, ascospores [eight] fully differentiated); and class E (perithecium empty, no asci present, ascospores discharged). The percentages of each developmental status at each monitoring period were calculated.

Germination of ascospores. This study was conducted with the leaf samples collected in Catalonia in 2017. The viability of ascospores was estimated by determining the germination percentages at each sampling period. From the same leaf samples used in the study on fruiting bodies development, a sufficient amount of perithecia containing mature ascospores was obtained. The perithecia were bisected, and their content was suspended in a 1.5-ml Eppendorf tube containing $1 \mathrm{ml}$ of distilled water. A volume $(200 \mu \mathrm{l})$ of the ascospore suspension was spread over a potato dextrose agar (PDA; Difco; Becton, Dickinson \& Co.) plate amended with streptomycin sulfate at $100 \mathrm{IU}$ streptomycin ml${ }^{-1}$ and incubated at $20^{\circ} \mathrm{C}$. Fifty randomly chosen ascospores per location and sampling date were counted (five replicates of 10 ascospores each) and classified into germinated and nongerminated categories by using a light microscope $(\times 250)$ at two intervals: 4 and $24 \mathrm{~h}$ after plating. An ascospore was recorded as germinated when the germ tube was greater than half the width of the ascospore as similarly described by Habibi and Banihashemi (2015).

Disease infectivity and incubation periods. The disease infectivity and incubation periods were studied in two locations in Andalusia (Córdoba) and Catalonia (Borges) for 1 (2016) and 3 (2015 to 2017) years, respectively. For each location and year, a group of 130 1-year-old Tarraco plants was kept in a greenhouse at IFAPA and IRTA facilities away from an eventual exposure to natural RLB infections. From February to August each year, 10 different plants from the group were brought every 2 weeks to the experimental orchards and left to be RLB infected under natural conditions. This resulted in a total of 13 recordings per each year and location. After the 2-week exposure to the disease, trap plants were removed from the field and taken back to the greenhouse, where they were monitored weekly from February to October to check for the expression and evolution of RLB symptoms. Numbers of apparently healthy and RLB-affected leaves in each plant were recorded, and the proportion of RLBaffected leaves (incidence) was calculated and averaged for each monitoring period. The infectivity period was determined as the period in which RLB-symptomatic leaves were detected along the experiment. The incubation period was estimated by determining the time (in weeks) between the initial exposure in the orchards and the consistent appearance of disease foliar symptoms minus 1 week to correct the 2-week exposure interval with its intermediate point.

Weather data. Main meteorological variables, namely temperature $(T), \mathrm{RH}$, and accumulated rainfall were recorded daily in the experimental areas throughout the monitored years. Data from three automatic weather stations included in the weather network services of the regional governments were used. The weather station in Gandesa was located $<100 \mathrm{~m}$ away from the experimental area. The weather station was about $9 \mathrm{~km}$ away in the case of Borges, and it was about $1 \mathrm{~km}$ away in the case of Córdoba. All recorded meteorological data were considered as representative of the weather conditions at the experimental sites. Raw meteorological data were summarized with 14 weather variables: maximum, minimum, and mean daily $T$; maximum and mean $\mathrm{RH}$; accumulated rainfall; number of rainy days (days with rainfall $\geq 0.2 \mathrm{~mm}$ ); accumulated vapor pressure deficit (VPD); number of wet days (see below); accumulated low $T$ in wet days $(50-T)$; and the number of days with mean daily $T$ measurements of $<10^{\circ} \mathrm{C}$, from 10 to $20^{\circ} \mathrm{C}$, and $\geq 20^{\circ} \mathrm{C}$. In addition, number of days considered both wet and with mild $T\left(10^{\circ} \mathrm{C} \leq T<\right.$ $20^{\circ} \mathrm{C}$ ) were also recorded because those conditions are thought to be potentially optimal for RLB development. Daily VPD was calculated from mean daily $T$ and mean RH according to the modified equation of Buck (1981) as described by Rossi et al. (2009):

$$
\begin{array}{r}
V P D(\text { hectopascals })=(1-R H / 100) \times 6.11 \\
\left.\quad \times \exp \left[\left(17.47 \times T_{\text {mean }}\right) / 239+T_{\text {mean }}\right)\right]
\end{array}
$$

Days were considered wet when VPD was $\leq 4 \mathrm{hPa}$ or accumulated rainfall was $\geq 0.2 \mathrm{~mm}$. The accumulation of low $T$ in wet days was measured as the sum of $50-T$ only in wet days. The 14 weather variables were calculated for the following time intervals: (i) from the previous 7- and 14-day periods of each monitoring date, (ii) from months between June and January, (iii) from the subdivisions from June to September (stage 1) and from October to January (stage 2) in the whole monitoring period indicated in ii, and (iv) from all of the infectivity periods of trap plants. This resulted in a total number of 182 weather variables (14 weather variables $\times 13$ time intervals).

Data analysis. Data obtained from the primary inoculum monitoring as well as incubation and infectivity periods were analyzed using Statistix v.10 (Analytical Software). Unless otherwise stated in text and figures, mean values are shown together with their corresponding standard errors. In the primary inoculum monitoring, factorial analysis of variance (ANOVA) was performed to test main effects and interactions of location and evaluation year on the ascospores amounts recorded periodically. These comparisons were performed by considering only the crushing method of ascospores extraction because it was only the common ascospore extraction method used in all studied locations. In an exploratory analysis and to avoid missing data because of differences in the monitoring start and ending dates among locations, only 13 matching data per year and locations were used (i.e., for the period between mid-February and early August in all years and locations). In further analyses made separately on the location basis, all recorded data were used. Data were tested for normality, homogeneity of variances, and normally distributed residual patterns using analytical tools of the statistical package. Logarithmic transformations were carried out when necessary. Treatment means were compared using Fisher's protected least significant difference at $\alpha=0.05$.

A regression model was fitted to describe the relationship between the ascospore counts from the two different ascospores extraction methods used in this study. Spearman's rank correlation coefficients ( $\rho)$ were calculated from the following variables: (i) the ascospore counts obtained by the crushing method in each evaluation period expressed as a proportion of the total accumulated counts during the selected period between mid-February and early August $\left(A S C_{\text {rate }}\right)$ and the weather variables observed within the 7- and 14-day periods previous to each ascospore count; (ii) the total ascospore counts during the season, total ascospores number in the previous year, and weather variables calculated from months between June to January and stages 1 and 2; and (iii) RLB incidence in trap plants and the weather variables from infectivity periods and ascospores counts at the end of the infectivity period. To avoid misunderstood and random variable associations (Fernández-Escobar et al. 2018), only associations with $\rho>0.500$ and $P<0.05$ between variables were considered strong and reliable enough. Therefore, only these relationships were considered in this work.

To analyze the possible influence of location and sampling period on the development and maturation of $P$. amygdalinum fruiting bodies, an ordinal logistic regression was performed in R v.3.5.1 (https:// www.R-project.org/) with the clm (cumulative link models) function included in the package "ordinal" (Christensen 2018).

\section{Results}

Monitoring of primary inoculum. An exploratory ANOVA test showed that the annual mean amount of RLB potential inoculum, as estimated by the ascospore counts per gram of leaf (agl), was significantly influenced by the experimental location $(P=0.007)$, the evaluation year $(P=0.039)$, and their interaction $(P=0.011)$. Because of 
interactions, further ANOVA tests were performed on data subsets according to their location origin. In general, the ascospore production period extended from January to August among the studied areas and seasons (Fig. 1). Highest amounts of ascospores were recorded in Córdoba, whereas those values of Borges and Gandesa were about a 10th of the amounts recorded in Córdoba. The Borges/Gandesa group did not differ from Borges and Gandesa $(P=0.922)$ in terms of mean annual ascospore amounts. In Córdoba, higher amounts of ascospores were observed in 2014 and 2015 in comparison with 2016, whereas in Borges and Gandesa, a higher amount of ascospores was observed in 2017 than in previous years (all $P<0.001$ ).

In Córdoba, mean ascospore amounts of $P$. amygdalinum obtained by leaf crushing were in the range from $1 \times 10^{6}$ to $6 \times 10^{6}$ agl (in 2014 and 2016), whereas about a 10-fold higher annual mean (i.e., $2 \times 10^{7}$
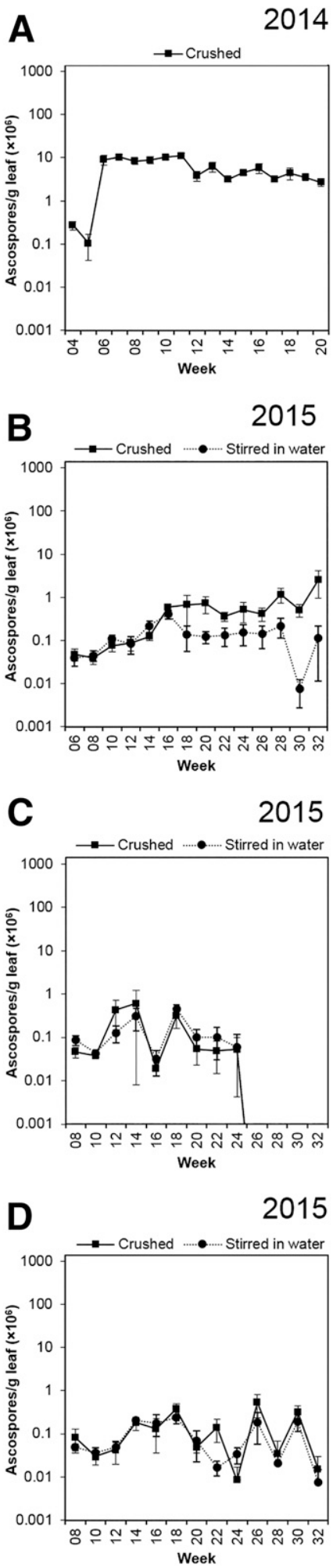

2015

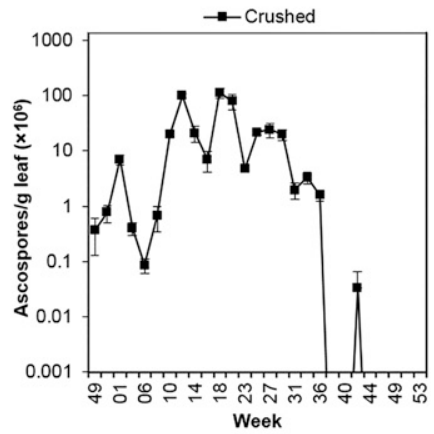

2016

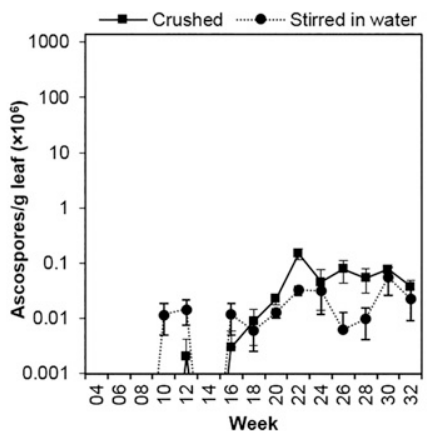

2016

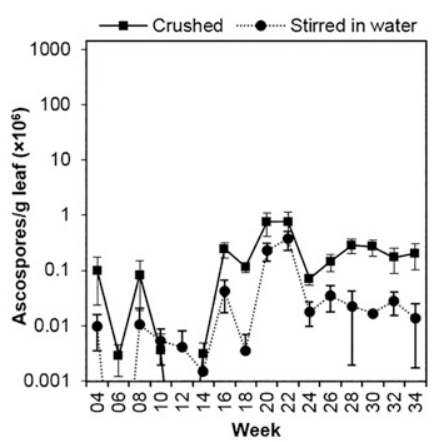

2016

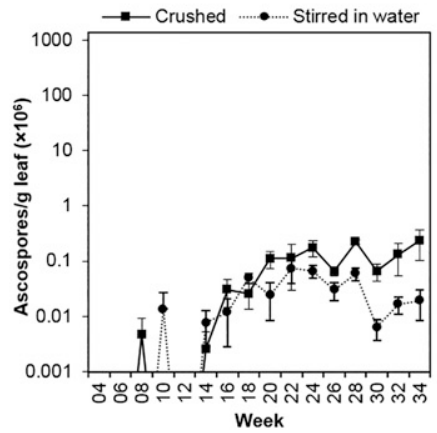

2016

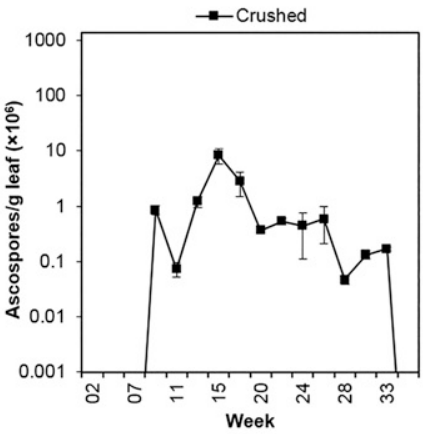

2017

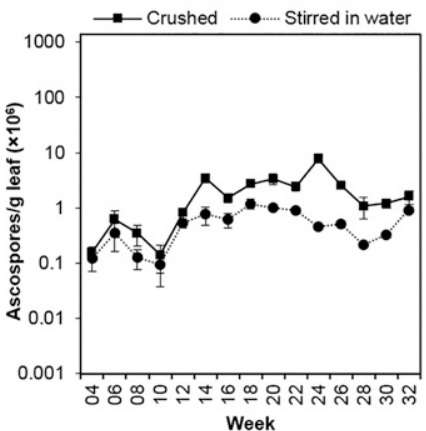

2017

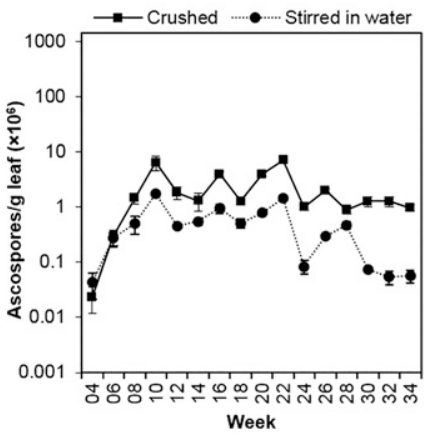

2017

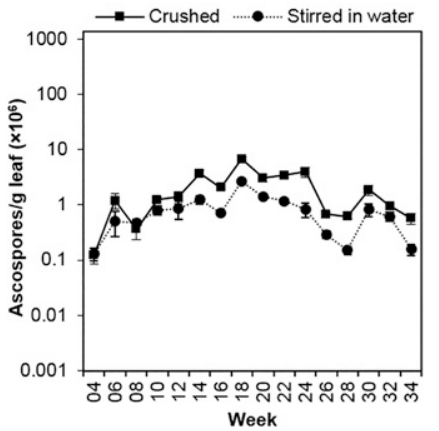

Fig. 1. Dynamics of Polystigma amygdalinum ascospores extracted from infected almond leaves during a 3-year monitoring period conducted in two almond-growing regions in Spain. Specific locations and monitoring periods: A, Córdoba (2014 to 2016), B, Gandesa (2015 to 2017), C, Les Borges Blanques (2015 to 2017), and D, leaves taken from Gandesa to Les Borges Blanques (2015 to 2017). 
agl) was estimated in 2015 (Fig. 1A). In 2014, ascospores in Córdoba were recorded early at the beginning of the season in January and remained quite stable at about $1 \times 10^{7}$ agl thereafter. In 2015, higher amounts of ascospores were mainly detected in a 6-month interval (i.e., March to August) and ranged between $1 \times 10^{6}$ and $1 \times 10^{8}$ agl within this period. In 2016, ascospores were detected between March and June and peaked up to $8 \times 10^{6}$ agl in April (Fig. 1A). In the Catalan locations of Borges and Gandesa, the presence of ascospores was detected from January to August, with some exceptions: no recordings after mid-June in 2015 in Borges and no or occasional low recordings at the beginning of the season in 2016 in Gandesa and Borges/Gandesa (Fig. 1B to D). Mean annual ascospore amounts obtained from crushed leaves were mostly in the range from $1 \times 10^{5}$ to $1 \times 10^{6}$ in 2015 and 2017 and between $1 \times 10^{4}$ and $1 \times$ $10^{5}$ in 2016, with several occasional peaks along the seasons. Occurrence of those peak values in ascospore amounts was variable among locations and years, and a pattern of peak occurrence was not clearly observed (Fig. 1). Dynamics of the RLB inoculum potentials along the season were similar in the cases of Gandesa and Borges/ Gandesa in 2015 and 2016 and slightly different from Borges within the same years. However, dynamics of ascospore amounts in 2017 were similar for the three Catalan leaf sources (Fig. 1B to D).

Ascospores amounts obtained through the stirring bath technique were consistently lower than those obtained by crushing (Fig. 1B to D). A significant linear relationship $\left(P<0.001, R^{2}=0.6721\right)$ between the log-transformed data of the two ascospore extraction methods was found as follows:

$$
\log \left(\text { Ascospores }_{\text {stirring }}\right)=1.1619+0.7128 \times \log \left(\text { Ascospores }_{\text {crushing }}\right)
$$

The equivalent power function was, therefore:

$$
\text { Ascospores }_{\text {stirring }}=14.5180 \times\left(\text { Ascospores }_{\text {crushing }}\right)^{0.7128}
$$

Moreover, there were no significant differences between samples from different origins (Borges and Borges/Gandesa) that were obtained with either extraction method $(P=0.621$ and $P=0.497$ for crushing and stirring, respectively).

Associations with $\rho>0.500$ and $P<0.05$ between the rate of ascospore amounts per season $\left(A S C_{\text {rate }}\right)$ and any tested weather variable were not found. However, the total amount of ascospores per season was only significantly correlated with weather-derived variables of stage 2 (October to January), which resulted in significant $(P<$ 0.05) $\rho$ values $>0.700$ in the following cases: mean RH $(\rho=$ $0.767)$, accumulated rainfall $(\rho=0.717)$, number of raining days ( $\rho=0.728)$, and number of days with mean daily $T$ of $>20^{\circ} \mathrm{C}(\rho=$ 0.706). Moreover, in October, the mean of maximum RH ( $\rho=$ $0.783)$, the accumulated rainfall $(\rho=0.733)$, and the number of days with mean daily $T$ of $\geq 20^{\circ} \mathrm{C}(\rho=0.706)$ were positively correlated with the total amount of ascospores per season. On the other side, only the number of days with daily mean $T$ from 10 to $20^{\circ} \mathrm{C}$ in October was negatively correlated $(\rho=-0.792)$ with the total amount of ascospores. In January, accumulated rainfall also showed a positive correlation with the total amount of ascospores per season $(\rho=$ 0.783). No more associations were found between the seasonal total ascospore amounts and weather variables for the remaining months of stage 2 .

Development of fruiting bodies. The development and maturation of perithecia along the season were confirmed through the observation that immature stages (A and B) were prevalent at the beginning of the experimental period, whereas mature stages $(C$, $\mathrm{D}$, and E) were mainly recorded later in the season (Fig. 2). Results from the ordinal logistic regression analysis on the whole dataset showed that all analyzed factors and their interactions, except for the interaction location $\times$ week, were significant (results not shown). Because of interactions, further ordinal logistic regressions were performed on data subsets according to the location of sampled leaves. In addition, datasets from Borges and Borges/ Gandesa were combined into a single dataset to evaluate the influence of the geographical origin of samples. Separate analyses of each location subset showed the significance of factors sampling period, year, and their interaction (all $P<0.001$ ). However, the origin of leaf samples in the Borges and Borges/Gandesa subsets was not found to be significant $(P=0.262)$; the interactions were also not found to be significant: origin $\times$ sampling period $(P=0.618)$, origin $\times$ evaluation year $(P=0.262)$, and origin $\times$ sampling period $\times$ evaluation year $(P=0.618)$.

In Gandesa, fully mature perithecia (D) were observed rarely in 2016, and the percentages of this class never exceeded $20 \%$ throughout the assay. However, mature perithecia with percentages $\geq 40 \%$ were detected in 2017 from early May (week 18) until the end of the experiment (Fig. 2, left panel). In Borges, mature ascocarps were more frequently detected than in Gandesa. Thus, class D ascocarps reached 80\% at mid-May 2016 (week 20) and remained in the range from 15 to $45 \%$ until August. In 2017, the percentage of mature perithecia observed in Borges prevailed to $>50 \%$ from late February (week 8) to the end of the experiment (Fig. 2, center panel). Regarding the Borges/Gandesa samples, maturation of ascocarps behaved similarly as that from Borges as shown earlier by the nonsignificance of the geographical origin factor and its interactions in the statistical analyses. Thus, percentages of $>50 \%$ in class D perithecia in 2017 prevailed in almost every week from mid-February on (Fig. 2, right panel).

Ascospore germination. Ascospores of $P$. amygdalinum germinated on PDA as earlier as $4 \mathrm{~h}$ after plating, but the highest percentages of ascospore germination were observed at $24 \mathrm{~h}$ of incubation (Fig. 3). In general, germination percentages at $24 \mathrm{~h}$ ranged from 12 to $44 \%$ for all leaf sample origins, with mean values for each leaf origin as follows: Gandesa, $16.6 \pm 3.8 \%$; Borges, $19.2 \pm 1.5 \%$; and
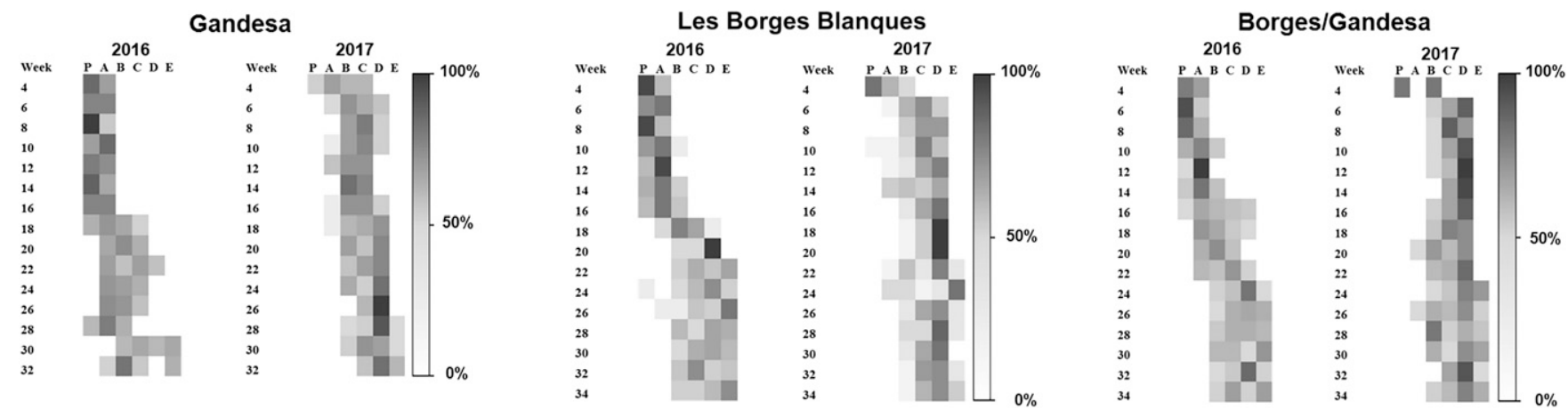

Fig. 2. Development of Polystigma amygdalinum fruiting bodies on almond leaves in 2 consecutive years and for three sample origins (Gandesa, Les Borges Blanques, and Borges/Gandesa). Results are shown in grayscale as percentages of fruiting bodies $(n=20)$ for each sampling period. A, differentiated immature perithecium with undifferentiated asci and ascospores; B, immature perithecium with differentiated asci and undifferentiated ascospores; $\mathrm{C}$, immature perithecium and differentiated asci with fewer than eight ascospores per ascus; D, mature perithecium and asci with eight ascospores per ascus; E, empty perithecium without asci and ascospores; P, pycnidia, no perithecia present. 
Borges/Gandesa, $20.9 \pm 1.2 \%$. In Gandesa, the highest germination percentage $(44.0 \pm 8.0 \%)$ was observed in mid-July (week 28 ), whereas in Borges, the maximum $(28.0 \pm 2.0 \%)$ occurred in midApril (week 16). Ascospores from the Borges group showed consistently $\geq 20 \%$ of germination during the first half of the monitoring period (Fig. 3). Similarly, ascospores from the Borges/Gandesa group showed the higher germination percentage $(30.0 \pm 2.0 \%)$ in April, just as the samples from Borges did.

Disease infectivity and incubation periods. Trap plants exposed in Córdoba and Borges showed that RLB infections occurred from March (week 9) to late July (week 30), although higher infection percentages were mainly detected from week 9 to week 18 (i.e., from March to early May) (Fig. 4). Moreover, the incidence of RLB in trap plants was positively correlated with the number of days with mean daily $T$ from 10 to $20^{\circ} \mathrm{C}\left(10 \leq T<20^{\circ} \mathrm{C} ; \rho=0.526, P=0.001\right)$ and the number of days both wet and with mild $T(V P D \leq 4 \mathrm{hPa}$ or $R \geq$ $0.2 \mathrm{~mm}$ and $\left.10 \leq T<20^{\circ} \mathrm{C} ; \rho=0.632, P<0.001\right)$.

Overall incidence in Córdoba was higher than in Borges in 2016 because infections in Córdoba were ranging from 30 to $70 \%$ within weeks 9 to 14, whereas equivalent values in Borges were ranging between 5 and $20 \%$ (Fig. 4). However, no differences in mean RLB incidence of trap plants $(P=0.064)$ between Borges $(5.54 \pm$ $5.60 \%)$ and Córdoba $(26.55 \pm 6.19 \%)$ were detected. Data collected in Borges in 3 consecutive years (2015 to 2017) indicated that infections decreased drastically in June, and only sporadic infections were detected later, coinciding with daily mean $T$ of $>20^{\circ} \mathrm{C}$ in this period (Fig. 4). In addition, no differences in RLB incidence of trap plants $(P=0.167)$ were detected in Borges when comparing all 3 monitored years.

The incubation periods estimated from the data recorded in 2015 to 2017 in Borges were mostly between 5 and 10 weeks, but extreme values (from 2 to 12) were occasionally recorded (Fig. 5). The duration of the incubation period tended to decrease from week 20 in 2016 (Fig. 5), but this trend was not observed in 2015 and 2017 because correlations were not significant (data not shown).

\section{Discussion}

Some key aspects of the $P$. amygdalinum epidemiology have been studied from 2013 to 2017 in two almond-growing regions in Spain, namely Andalusia and Catalonia, which included the potential primary inoculum development and the incubation and infectivity periods. Correlation analyses between biological and meteorological
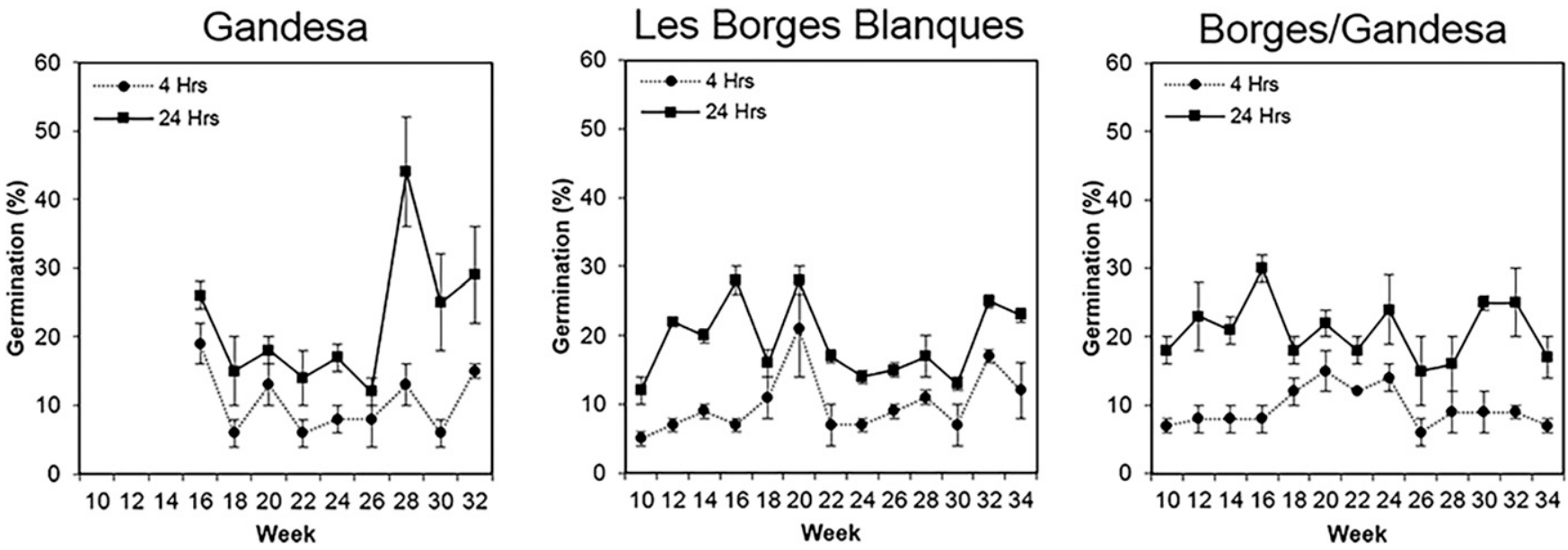

Fig. 3. Germination percentages of Polystigma amygdalinum ascospores $(n=50)$ recorded from three leaf sample origins (Gandesa, Les Borges Blanques, and Borges/Gandesa).
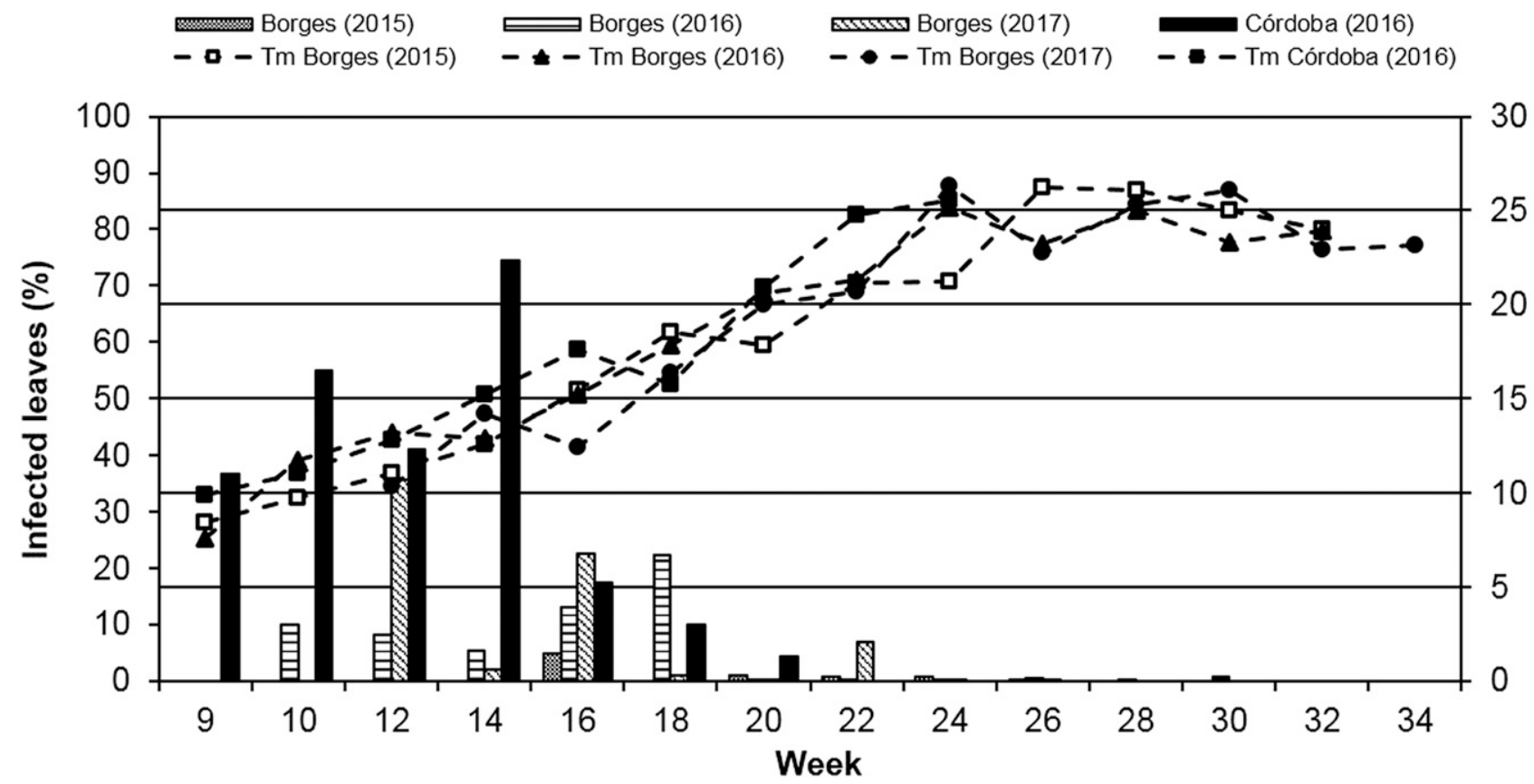
data contributed to a better understanding of the pathogen lifecycle on almond.

Previous data about the RLB epidemiology and strategies to control this disease at worldwide level were based on studies conducted in Iran and Lebanon, which reported on the production of ascospores, the disease infection period, and the control of RLB using fungicides (Ashkan and Assadi 1974; Banihashemi 1990; BaytTork et al. 2014; Ghazanfari and Banihashemi 1976; Saad and Masannat 1997). In Spain, previous knowledge of the RLB disease included some field observations about symptom incidence and severity (Almacellas 2014; Ollero-Lara et al. 2016a, b) and cultivar susceptibility (Ollero-Lara et al. 2019). Thus, this work aimed to increase the knowledge on the dynamics of major aspects of the RLB disease in our country, where environmental conditions for almond-growing areas could be different from those of previously studied cases in Iran and Lebanon.

In previous research conducted in Iran and Lebanon, a main period from April to May was reported for the potential primary inoculum availability (Ashkan and Assadi 1974; Banihashemi 1990; Saad and Masannat 1997), which coincides with that observed in Córdoba and Borges in 2014 and 2015, respectively. However, an extended period of ascospore availability (i.e., from February to August) was repeatedly observed in later seasons in our study. This suggests a longer period when primary inoculum of RLB can be present in Spain, thus increasing the potential risk of infections during favorable periods. The amounts of ascospores recorded in this study cannot be compared with data on ascospore counts reported by Banihashemi (1990) and Saad and Masannat (1997) because methods in those latter studies were based on the quantification of captured airborne ascospores. In our study, the ascospore extraction methods from leaves may have overestimated the amounts of available ascospores, especially when extracting ascospores by crushing. Fruiting bodies can be physically broken when leaves are crushed so that the whole perithecia content is released to the medium, and higher ascospore amounts can be, therefore, recorded.

Banihashemi (1990) suggested that changing environmental conditions could influence ascospore release and RLB infections. In this study, we observed that total amounts of ascospores per season were correlated positively with environmental conditions of previous fall and winter seasons (October to January), especially with variables related to water availability and to a lesser extent, temperature. Thus, $P$. amygdalinum benefits from the hydration of fallen leaves and $T$ of $>20^{\circ} \mathrm{C}$ during fall, mainly in October, to produce higher inoculum potentials during the next season. However, Ghazanfari and Banihashemi (1976) reported that $P$. amygdalinum requires $T$ of $<10^{\circ} \mathrm{C}$ in fall and winter to favor ascocarp development in the next season, which is in contrast with our results. Further research is, therefore, needed to clarify the influence of fall and winter environmental conditions on the seasonal dynamics of the disease. However, correlations must be treated with caution to avoid spurious associations (Fernández-Escobar et al. 2018). Geographical conditions may also play a major role in the primary inoculum development as confirmed by the sharp differences in annual potential inoculum amounts observed in Andalusia and Catalonia. These results confirm the idea that RLB of almond needs to be studied in each region where it is reported. Moreover, it is advisable to conduct a multiyear monitoring of the primary inoculum because, as reported here, highly variable ascospore amounts can be recorded among seasons.

The maturation of $P$. amygdalinum perithecia and ascospores was rather related to seasonal weather conditions than to the geographical origin of samples. However, a disparity between maturity of fruiting bodies and primary inoculum dynamics was detected in some cases. Thus, perithecia reached maturation late in the season in 2016 in all locations, whereas free ascospores were detected from the first weeks of the year until the end of the experiment. We hypothesize that this might have been owing to the sample size of the analyzed leaves, which could have been insufficient to adequately represent how fruiting bodies developed in the leaf litter along the season. Gadoury et al. (1992) reported a disparity between morphological maturity of ascospores and physiological maturity of asci in the apple scab fungus, Venturia inaequalis, which could be comparable with our results. The authors found that discharge of ascospores was recorded as early as asci were rated as mature in approximately 10 to $15 \%$ of full maturity.

In our study, ascospores were able to germinate but failed to grow further, which is in agreement with data reported by Habibi and Banihashemi (2015). However, germination percentages after $24 \mathrm{~h}$ of incubation were consistently low, well $<30 \%$ in most cases. These low germination percentages could be related to the biotrophic nature of the pathogen (Cannon 1996; Habibi and Banihashemi 2015 ) or even to unknown environmental factors. Data on ascospore germination could be useful in a first stage for testing fungicides in vitro against $P$. amygdalinum as well as in the development of mechanistic predictive models on RLB epidemiology.

The natural RLB infections observed in trap plants occurred between week 9 and week 22 (February to May), despite the geographical location of almond orchards. Moreover, we found that $T$ between 10 and $20^{\circ} \mathrm{C}$ promoted infection by $P$. amygdalinum, particularly when associated with wetness conditions. Rainfall and high RH could provide adequate moisture for ascospore dispersal and subsequent infection. The importance of $T$ and moisture (hydrothermal variables) is well characterized in many pathosystems (Agrios 2005), and these variables are generally known to explain plant disease development (Lovell et al. 2004), such as in the Plasmopara viticola-grape (Rossi et al. 2008) and the Venturia pirina-pear (Rossi et al. 2009) pathosystems. Moreover, infections in Andalusia and Catalonia declined when $T$ raised to $>20^{\circ} \mathrm{C}$, thus suggesting that warmer temperatures were inhibiting RLB infections. It is known that optimum temperature for ascospore germination and appressorium formation among Phyllachora species is 10 to $20^{\circ} \mathrm{C}$ (Banihashemi 1990; Dittrich et al. 1991; Parbery 1963) and that $T$ of $>25^{\circ} \mathrm{C}$ inhibits appressorium formation (Habibi and Banihashemi 2015). These data would be compatible with fewer infections of $P$. amygdalinum being detected in summer. Our results showed that the incubation period mostly ranged between 5 and 10 weeks but can be as long as 12 weeks in spring and as short as 2 weeks in summer. These results differ clearly from those reported by Ashkan and Assadi (1974), who estimated a narrower incubation period of 30 to 35 days, and those by Banihashemi (1990), who reported a similar period (30 to 40 days).

Although $P$. amygdalinum has been considered as a biotrophic pathogen (Cannon 1996), other plant pathogens with a similar multistage development as $P$. amygdalinum are classified as hemibiotrophic pathogens, such as Mycosphaerella graminicola (Fuckel) J Schröt., Pyricularia oryzae Cavara, and Colletotrichum spp. (Marshall et al. 2011; Mentlak et al. 2012; O'Connell et al. 2012). This hemibiotrophic lifestyle can be easily recognized in P. amygdalinum: (i) a long initial biotrophic phase with the pathogen spreading inside living host cells without causing noticeable host cell damage in spring and summer and (ii) a short necrotrophic phase in which pathogen growth causes multiple host cell death and the darkening of leaf stroma (Saad and Masannat 1997; Zúñiga et al. 2019). Lastly, P. amygdalinum continues the necrotic phase on fallen leaves (from October to January), which is before the final development and maturation of perithecia and ascospores.

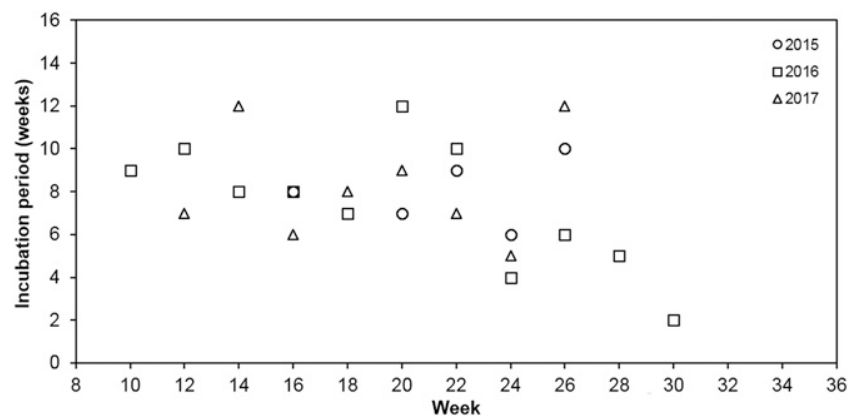

Fig. 5. Incubation periods of almond red leaf blotch in cultivar Tarraco susceptible almond trees exposed to natural infections in Les Borges Blanques (2015 to 2017). 
In this work, we have studied the primary inoculum dynamics, the development of the fruiting bodies, and the germination of ascospores as well as the natural infections of the RLB. The results reported here can help in building a future prediction model, which would integrate some key biological aspects of $P$. amygdalinum with the environmental conditions met in each almond-growing area. Thus, predicting risk events for RLB infection could help in making more effective decisions on management programs and control strategies.

\section{Acknowledgments}

The authors thank F. Luque and A. López-Moral for their skillful technical assistance.

\section{Literature Cited}

Agrios, G. N. 2005. Plant Pathology, 5th Ed. Elsevier Academic Press, San Diego, CA. Almacellas, J. 2014. Síntomas, daños y métodos de control de la mancha ocre. Vida Rural 389:28-32.

Almacellas, J., and Marín, J. P. 2011. Control de plagas y enfermedades en el cultivo del almendro. Vida Rural 334:68-74.

Arquero, O. 2013. Manual del Almendro. Junta de Andalucía-Consejería de Agricultura, Pesca y Desarrollo Rural, Sevilla, Spain.

Ashkan, M., and Assadi, P. 1974. Red blotch of almond (Polystigma ochraceum) in Iran. Iranian J. Plant Pathol. 10:49-63.

Banihashemi, Z. 1990. Biology and control of Polystigma ochraceum, the cause of almond red leaf blotch. Plant Pathol. 39:309-315.

Bayt-Tork, D., Taherian, M., and Divan, R. 2014. Evaluation of some fungicides for controlling almond red leaf blotch (Polystigma amygdalinum). Int. J. Adv. Biol. Biomed. Res. 2:1011-1016.

Buck, A. L. 1981. New equations for computing vapour pressure and enhancement factor. J. Appl. Meteorol. 20:1527-1532.

Cannon, P. F. 1996. Systematics and diversity of the Phyllachoraceae associated with Rosaceae, with a monograph of Polystigma. Mycol. Res. 100:1409-1427.

Christensen, R. H. B. 2018. Ordinal-Regression Models for Ordinal Data. R Package Version 2018.8-25. http://cran.r-project.org/package=ordinal/

Dittrich, U., Hock, J., Kranz, J., and Renfro, B. 1991. Germination of Phyllachora maydis ascospores and conidia of Monographella maydis. Cryptogam. Bot. 2: 214-218.

FAOSTAT. 2019. Food and Agriculture Data. http://www.fao.org/faostat/en/\#data

Farr, D. F., and Rossman, A. Y. 2019. Fungal Databases, U.S. National Fungus Collections, ARS, USDA. https://nt.ars-grin.gov/fungaldatabases/

Fernández-Escobar, R., Trapero, A., and Domínguez, J. 2018. Experimentación en Agricultura. Consejería de Agricultura y Pesca, Junta de Andalucía, Sevilla, Spain.

Gadoury, D. M., Seem, R. C., Rosenberger, D. A., Machardy, W. E., and Berkett, L. P. 1992. Disparity between morphological maturity of ascospores and physiological maturity of asci in Venturia inaequalis. Plant Dis. 76:277-282.

Ghazanfari, J., and Banihashemi, Z. 1976. Factors influencing ascocarp formation of Polystigma ochraceum. Trans. Br. Mycol. Soc. 66:401-406.

González-Fragoso, R. 1927. Botánica Criptogámica Agrícola. Espasa-Calpe, Madrid, Spain

Habibi, A., and Banihashemi, Z. 2015. Ascospore germination and appressorium formation in vitro of Polystigma amygdalinum and its survival period. Iranian J. Plant Pathol. 51:461-469.

Habibi, A., and Banihashemi, Z. 2016. Mating system and role of pycnidiospores in biology of Polystigma amygdalinum, the causal agent of almond red leaf blotch. Phytopathol. Mediterr. 55:98-108.

Habibi, A., Banihashemi, Z., and Mostowfizadeh-Ghalamfarsa, R. 2015. Phylogenetic analysis of Polystigma and its relationship to Phyllachorales. Phytopathol. Mediterr. 54:45-54.

Lin, A., and Szteinberg, A. 1992. Control of the almond disease Polystigma by urea treatments. Alon Hanotea 47:15-21.
Lovell, D. J., Powers, S. J., Welham, S. J., and Parker, S. R. 2004. A perspective on the measurement of time in plant disease epidemiology. Plant Pathol. 53: 705-712.

MAPA. 2019. Ministerio de Agricultura y Pesca, Alimentación y Medio Ambiente. https://www.mapama.gob.es/es/estadistica/temas/estadisticas-agrarias/ agricultura/superficies-producciones-anuales-cultivos/

Marshall, R., Kombrink, A., Motteram, J., Loza-Reyes, E., Lucas, J., HammondKosack, K. E., Thomma, B. P. H. J., and Rudd, J. J. 2011. Analysis of two in planta expressed LysM effector homologs from the fungus Mycosphaerella graminicola reveals novel functional properties and varying contributions to virulence on wheat. Plant Physiol. 156:756-769.

Mentlak, T. A., Kombrink, A., Shinya, T., Ryder, L. S., Otomo, I., Saitoh, H., Terauchi, R., Nishizawa, Y., Shibuya, N., Thomma, B. P. H. J., and Talbot, N. J. 2012. Effector-mediated suppression of chitin-triggered immunity by Magnaporthe oryzae is necessary for rice blast disease. Plant Cell 24 : 322-335.

Miarnau, X., Torguet, L., Zazurca, L., Maldonado, M., Girabet, R., Batlle, I., and Rovira, M. 2018. El futuro del almendro en España: ¿Será posible producir $4.000 \mathrm{~kg}$ de grano/ha? Horticultura 337:16-26.

Miarnau, X., Vargas, F. J., Montserrat, R., and Alegre, S. 2010. Aspectos importantes en las nuevas plantaciones de almendro en regadío. Rev. Fruticultura - Especial Almendro 2010:94-103.

O'Connell, R. J., Thon, M. R., Hacquard, S., Amyotte, S. G., Kleemann, J., et al 2012. Lifestyle transitions in plant pathogenic Colletotrichum fungi deciphered by genome and transcriptome analyses. Nat. Genet. 44:1060-1065.

Ollero-Lara, A., Agustí-Brisach, C., Lovera, M., Roca, L. F., Arquero, O., and Trapero, A. 2019. Field susceptibility of almond cultivars to the four most common aerial fungal diseases in southern Spain. Crop Prot. 121:18-27.

Ollero-Lara, A., López-Moral, A., Lovera, M., Raya, M. C., Roca, L. F., Arquero, O., and Trapero, A. 2016a. Las enfermedades del almendro en Andalucía. Rev. Fruticultura 49:166-183.

Ollero-Lara, A., Lovera, M., Roca, L. F., Arquero, O., and Trapero, A. 2016b. Susceptibilidad varietal del almendro a la mancha ocre en Andalucía. Vida Rural 412:14-22.

Parbery, D. 1963. Studies on graminicolous species of Phyllachora Fckl. I. Ascospores-their liberation and germination. Aust. J. Bot. 11:117-130.

Rossi, V., Caffi, T., Bugiani, R., Spanna, F., and Dellavalle, D. 2008. Estimating the germination dynamics of Plasmopara viticola oospores using the hydrothermal time. Plant Pathol. 57:216-226.

Rossi, V., Salinari, F., Pattori, E., Giosuè, S., and Bugiani, R. 2009. Predicting the dynamics of ascospore maturation of Venturia pirina based on environmental factors. Phytopathology 99:453-461.

Saad, A. T., and Masannat, K. 1997. Economic importance and cycle of Polystigma ochraceum, causing red leaf blotch disease of almond in Lebanon. OEPP/EPPO Bull. 27:481-485

Shabi, E. 1997. Disease management of the almond pathogens Glomerella cingulata, Polystigma ochraceum and Tranzschelia pruni-spinosae. OEPP/ EPPO Bull. 27:479-480.

Suzuki, Y., Hatakeyama, S., Harada, Y., and Tanaka, K. 2008. Polystigma fulvum, a red leaf blotch pathogen on leaves of Prunus spp., has the Polystigmina pallescens anamorph/andromorph. Mycoscience 49:395-398.

Torguet, L., Batlle, I., Alegre, S., and Miarnau, X. 2016. Nuevas plagas y enfermedades emergentes, una amenaza para el cultivo del almendro en España. Rev. Fruticultura 49:152-165.

Toscano-Underwood, C., Huang, Y. J., Fitt, B. D. L., and Hall, A. M. 2003. Effects of temperature on maturation of pseudothecia of Leptosphaeria maculans and L. biglobosa on oilseed rapestem debris. Plant Pathol. 52:726-736.

Vargas, F. J., Romero, M., Batlle, I., Rovira, M., Gispert, J. R., Romero, A., Alegre, S., and Miarnau, X. 2010. El programa de mejora de variedades de almendro del IRTA. Rev. Fruticultura - Especial Almendro 2010:10-23.

Zúñiga, E., Luque, J., and Martos, S. 2019. Lignin biosynthesis as a key mechanism to repress Polystigma amygdalinum, the causal agent of the red leaf blotch disease in almond. J. Plant Physiol. 236:96-104. 